\title{
Vacinas contra Coronavírus (COVID-19; SARS-COV-2) no Brasil: um panorama
}

\section{geral}

\author{
Coronavirus vaccines (COVID-19; SARS-COV-2) in Brazil: an overview
}

Vacunas contra el coronavirus (COVID-19; SARS-COV-2) en Brasil: una descripción general

E-mail: mauríciomarques15@outlook.com

Isabella Campelo Soares de Carvalho

ORCID: https://orcid.org/0000-0002-5149-2223 Instituto de Ensino Superior do Vale do Parnaíba, Brasil

E-mail: isabellacampelosc@outlook.com

João Vitor Messias Esperandio ORCID: https://orcid.org/0000-0003-0184-4531 Instituto Tocantinense Presidente Antonio Carlos, Brasil

E-mail: jvmessiasesperandio@ hotmail.com

Anna Carmela Araujo Benoliel Vasconcelos ORCID: https://orcid.org/0000-0002-1126-6766 Instituto Tocantinense Presidente Antonio Carlos, Brasil

E-mail: anacarmelaaraujo@hotmail.com

José Guilherme Férrer Pompeu ORCID: https://orcid.org/0000-0001-9038-0833 Universidade Federal do Piauí, Brasil E-mail: gpompeu8@gmail.com

Victor Eulálio Sousa Campelo ORCID: https://orcid.org/0000-0002-3715-4359 Universidade Federal do Piaú, Brasil E-mail: dr.vcampelo@gmail.com

Eudes Rufino da Silveira Filho ORCID: https://orcid.org/0000-0003-0360-1322 Centro Universitário UNINOVAFAPI, Brasil E-mail: personalgigaeudes@gmail.com

Melka Luciana Rocha de Paiva ORCID: https://orcid.org/0000-0002-5483-0873 Universidade Federal do Piauí, Brasil E-mail: Melkaluciana@gmail.com

Alessandro Monteiro Carvalho ORCID: https://orcid.org/0000-0001-8257-6916 Universidade Federal do Piauí, Brasil E-mail: alefarma443@yahoo.com.br

José Jonas Soares Guedes

ORCID: https://orcid.org/0000-0002-0858-3525

Centro Universitário Santo Agostinho, Brasil E-mail: jonassguedes@hotmail.com 


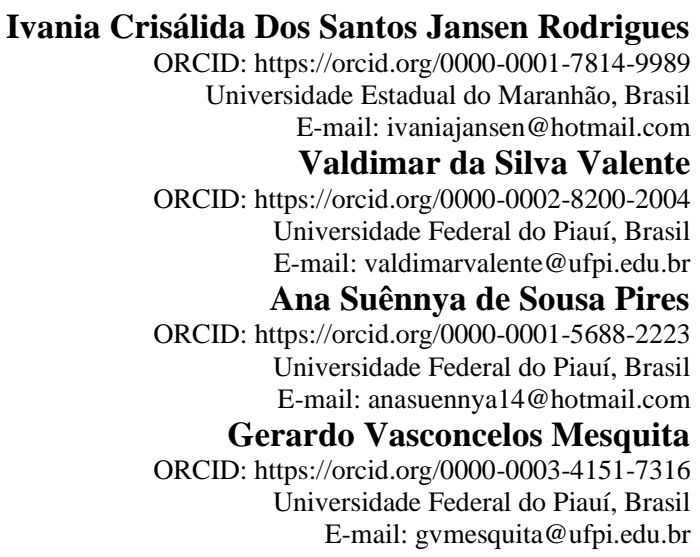

\section{Resumo}

O presente estudo teve como objetivo a importância da vacinação contra Coronavírus (COVID-19; SARS-COV-2) no Brasil, buscando descrever a sua eficácia e a importância da conscientização da imunização. Trata-se de uma revisão bibliográfica do tipo revisão integrativa da literatura (RIL), que apresenta abordagem qualitativa. Para a realização desse estudo, foram consultadas as bases de dados: Medical Literature Analysis and Retrieval System Online (MEDLINE), Scholar Google, Literatura Latino-americana e do Caribe em Ciências da Saúde (LILACS), Scientific Eletronic Library Online (SCIELO), Repositórios e Google acadêmico. Utilizou-se os Descritores em Ciências da Saúde (DeCS) de forma associada: "COVID-19", "vacina", "Brasil", "Imunização" e "Coronavírus". Os critérios de inclusão foram: artigos disponibilizados na íntegra, disponíveis nos idiomas português e inglês e publicados entre os anos de 2019 e 2021 . Após a aplicação dos critérios de inclusão, restaram 18 estudos. Ao longo da história observa-se que as práticas de vacinação programadas e organizadas evitam milhões de óbitos e controla a evolução de várias doenças. No Brasil, a cobertura vacinal se iniciou por dois grupos prioritários: profissionais da saúde por estarem na linha de frente e população idosa, pelo maior risco de morte por COVID-19 que aumenta com a idade, especialmente entre os portadores de doenças crônicas.

Palavras-chave: Covid-19; Vacina; Brasil; Imunização; Coronavírus.

\section{Abstract}

The present study aimed at the importance of vaccination against Coronavirus (COVID-19; SARS-COV-2) in Brazil, seeking to describe its effectiveness and the importance of raising awareness of immunization. This is a bibliographic review of the integrative literature review (RIL) type, which presents a qualitative approach. To carry out this study, the following databases were consulted: Medical Literature Analysis and Retrieval System Online (MEDLINE), Scholar Google, Latin American and Caribbean Health Sciences Literature (LILACS), Scientific Electronic Library Online (SCIELO), Repositories and Academic Google. The Descriptors in Health Sciences (DeCS) were used in an associated way: "COVID-19", "vaccine", "Brazil", "Immunization" and "Coronavirus". Inclusion criteria were: articles available in full, available in Portuguese and English and published between 2019 and 2021. After applying the inclusion criteria, 18 studies remained. Throughout history, it has been observed that programmed and organized vaccination practices prevent millions of deaths and control the evolution of various diseases. In Brazil, vaccination coverage began with two priority groups: health professionals, for being on the front line, and the elderly population, for the higher risk of death from COVID-19, which increases with age, especially among patients with chronic diseases.

Keywords: Covid-19; Vaccine; Brazil; Immunization; Coronavirus.

\section{Resumen}

El presente estudio apuntó a la importancia de la vacunación contra el Coronavirus (COVID-19; SARS-COV-2) en Brasil, buscando describir su efectividad y la importancia de crear conciencia sobre la inmunización. Se trata de una revisión bibliográfica del tipo revisión integradora de la literatura (EIR), que presenta un enfoque cualitativo. Para la realización de este estudio se consultaron las siguientes bases de datos: Medical Literature Analysis and Retrieval System Online (MEDLINE), Scholar Google, Latin American and Caribbean Health Sciences Literature (LILACS), Scientific Electronic Library Online (SCIELO), Repositories y Academic Google. Los Descriptores en Ciencias de la Salud (DeCS) se utilizaron de forma asociada: "COVID-19", "vacuna", "Brasil", "Inmunización" y "Coronavirus". Los criterios de inclusión fueron: artículos disponibles en su totalidad, disponibles en portugués e inglés y publicados entre 2019 y 2021. Después de aplicar los criterios de inclusión, quedaron 18 estudios. A lo largo de la historia se ha observado que las prácticas de vacunación programadas y organizadas previenen millones de muertes y controlan la evolución de diversas enfermedades. En Brasil, la cobertura de vacunación comenzó con dos grupos prioritarios: los profesionales de la salud, por estar en primera línea, y la población anciana, por el mayor riesgo de muerte por COVID19, que aumenta con la edad, especialmente entre los pacientes con enfermedades crónicas.

Palabras clave: Covid-19; Vacuna; Brasil; Inmunización; Coronavirus. 


\section{Introdução}

Os coronavírus (CoVs) são pertencentes a uma família que possui o RNA de fita simples. Além dos humanos, esses vírus infectam outros mamíferos e espécies de aves, incluindo gado e animal de estimação. O Coronavírus humanos (CoVsH), como HCoV-229E e HCoV-OC43, há muito tempo circulam na população e eles, causam infecções sazonais, em muitos casos com quanto leve do trato respiratório. O coronavírus de síndrome respiratória aguda grave (SARS-CoV), síndrome respiratória coronavírus do Oriente Médio (MERS-CoV) e SARS-CoV-2, que surgiram na população humana nos últimos 20 anos, possui uma patogenicidade elevada e atuam infectando células epiteliais brônquicas, pneumócitos e células do trato respiratório superior em humanos (Ventura; Aith; Rached, 2021).

A SARS-CoV-2 tem causado morbidade e mortalidade em alta escala em todo o mundo. Pesquisas sugerem efeitos residuais da infecção por SARS-CoV-2, como fadiga, dispneia, dor torácica, distúrbios cognitivos, artralgia e declínio na qualidade de vida. Além disso, pode-se observar danos celulares, por meio de uma resposta imune inata robusta com produção de citocinas inflamatórias e um estado pró-coagulante induzido pela infecção por SARS-CoV-2 podem contribuir para essas sequelas (Nalbandian et al., 2021).

Durante a infecção por coronavírus observa-se ligação específica da proteína spike (S) do coronavírus aos receptores de entrada celular, que foram identificados para vários coronavírus e incluem aminopeptidase N humana (APN; HCoV-229E), enzima conversora de angiotensina 2 (ACE2; HCoV-NL63, SARS-CoV e SARS-CoV-2) e dipeptidil peptidase 4 (DPP4; MERS$\mathrm{CoV})$. No decorrer do ciclo de vida intracelular, os coronavírus expressam e replicam seu RNA genômico para produzir cópias completas que são incorporadas às partículas virais recém-produzidas (V'kovski et al., 2021).

As primeiras infecções pelo COVID-19 foram localizadas na cidade de Wuhan, China, sugerindo que o vírus foi transmitido por animais que estavam sendo vendidos como alimentos exóticos para os seres humanos. O COVID-19 é transmitido na maior parte dos casos de pessoa para pessoa por meio de gotículas transportadas pelo ar, que são originários da tosse ou de espirros de uma pessoa infectada. Também é possível contrair uma infecção ao tocar em superfície contaminada e depois tocar sua própria boca, nariz ou olhos (Tesini, 2020).

Por conta disso, países estão adotando diversas medidas preventivas, entre elas: a limitação ou interrupção de voos internacionais, a fim de conter a disseminação. Pois, o mais apropriado é o desenvolvimento e uso de vacina visando conter o aumento de casos. Existem diversas tecnologias de vacinas possíveis em todo o mundo em diferentes estágios de desenvolvimento, as quais apresentam uma ampla gama de tecnologias, como: RNA mensageiro, baseado em DNA, nanopartículas, partículas sintéticas e modificadas como vírus, entre outras (Pang, 2020).

Além disso durante a pandemia observou-se uma redução em todo o processo de criação de vacina a um período de 12 a 18 meses. Lima, Almeida, Kfouri, (2021), realizaram a seguinte pergunta em sua pesquisa: será tudo isso possível sem que haja prejuízo da efetividade e segurança adequadas?. Pois aproximadamente 175 equipes de pesquisa em todo o mundo estão se dedicando para criação vacinas contra a COVID-19. Programas de desenvolvimento de vacinas são continuadamente atualizados pela Organização Mundial da Saúde (OMS), com projetos oriundos de fontes públicas e privadas.

Em março de 2021, o governo brasileiro buscou adotar à Covax Facility, dez meses depois, quando as tratativas internacionais estavam em fase final, a partir disso a imprensa internacional e brasileira descreveu esse episódio como uma adesão tardia. Mesmo com sistema universal de atenção à saúde - Sistema Único de Saúde (SUS), até o dia 10 de abril de 2021 , o Brasil tinha vacinado cerca de $10,7 \%$ de sua população, sendo considerado uma porcentagem baixa de vacinação. A vacina começou a ser aplicado em fevereiro de 2021, cerca de três meses após o início da campanha vacinal na Europa e nos EUA, onde as vacinas adotadas foram a da AstraZeneca (Covishield), importada e destinada a ser produzida pela Fundação Oswaldo Cruz (Fiocruz-Rio) e a coprodução com Insumo Farmacêutico Ativo (IFA) sino-brasileiro da Coronavac, conhecida por ser um vírus 
inativo que está sendo produzida pelo Instituto Butantan-São Paulo (Corrêa Filho; Ribeiro, 2021).

A partir disso o presente estudo teve como objetivo a importância da vacinação contra Coronavírus (COVID-19; SARSCOV-2) no Brasil, buscando descrever a sua eficácia e a importância da conscientização da imunização.

\section{Metodologia}

\subsection{Natureza do estudo}

A metodologia escolhida foi revisão bibliográfica do tipo revisão integrativa da literatura (RIL), que apresenta abordagem qualitativa e abrange os estudos com caráter empírico e teórico, identificando ideias já conhecidas sobre um assunto especifico em estudos realizados e gerando conhecimentos sobre resultados de distintos estudos (Mendes; Silveira; Galvão, 2008).

Para estruturar essa revisão seguiram-se 6 etapas metodológicas: identificação do tema e seleção da hipótese ou questão de pesquisa; estabelecimento de critérios para inclusão e exclusão de estudos; busca na literatura; avaliação dos estudos incluídos na revisão integrativa; Interpretação dos resultados; apresentação da revisão ou síntese do conhecimento. RIL se constitui por seis etapas representadas no Fluxograma 1 abaixo:

Fluxograma 1. Estrutura da revisão.

\section{$1^{\circ}$ - Identificação do tema e Elaboração das perguntas norteadoras \\ Quais as principais vacinas aplicadas contra COVID-19 no Brasil? \\ Qual a importância da imunização por meio da vacina?}
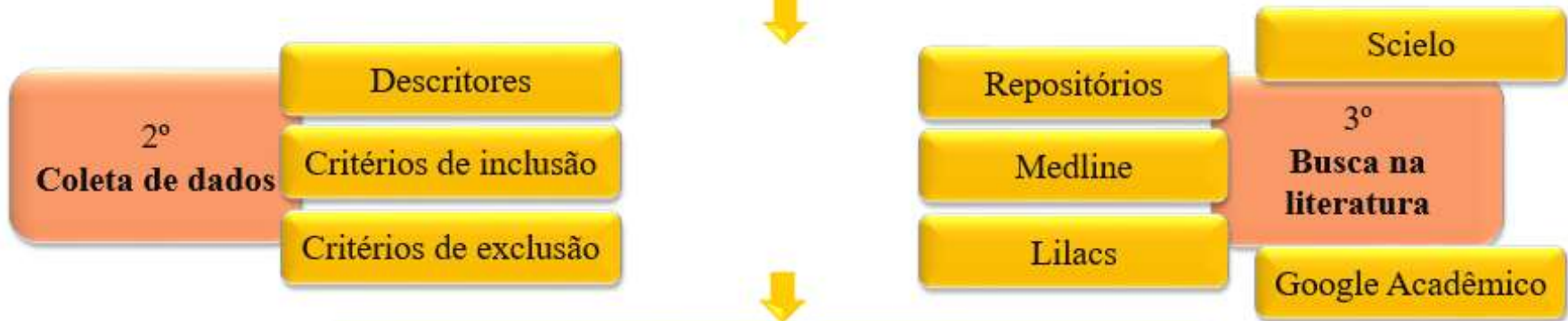

\section{$4^{0}$ - Analises críticas das informações a serem extraídas}

\section{$5^{\circ}$ - Interpretação dos resultados}

\section{$6^{\circ}$ - Apresentação da revisão}

Fonte: Autores (2021).

\subsection{Estratégia de busca}

Para a realização desse estudo, foram consultadas as bases de dados: Medical Literature Analysis and Retrieval System Online (MEDLINE), Scholar Google, Literatura Latino-americana e do Caribe em Ciências da Saúde (LILACS), Scientific Eletronic Library Online (SCIELO), Repositórios e Google acadêmico. Utilizou-se os Descritores em Ciências da Saúde (DeCS) 
de forma associada: "Covid-19", "vacina", "Brasil", "Imunização" e "Coronavírus".

As bases de dados utilizadas foram escolhidas por ser fonte de pesquisa para estudantes e profissionais da área da saúde, por isso, buscou-se identificar as publicações científicas que abordavam o tema deste estudo. Ao final da coleta de dados, foram selecionados os artigos que se adequaram aos objetivos, compondo o corpus de análise.

\subsection{Critérios de inclusão}

Os critérios de inclusão foram: artigos disponibilizados na íntegra, disponíveis nos idiomas português e inglês e publicados entre os anos de 2019 e 2021.

\subsection{Critérios de exclusão}

Os critérios de exclusão foram: artigos incompletos, cartas ao editor, debates, resenhas, resumos ou artigos publicados em anais de eventos, indisponíveis na íntegra e duplicados.

Para a análise crítica das literaturas foi realizada a análise de Bardin (2011), que consiste em um método que abrange todas as classes de documentos e textos e dividido em três etapas:

1. Pré-análise, nessa etapa ocorreu o acesso as literaturas por meio dos bancos de dados utilizando os descritores e filtros referentes aos critérios de inclusão e exclusão, com intuito de organizar o material a ser utilizado tornando-o operacional;

2. Exploração do material, ocorre a etapa de codificação do material selecionado, nessa fase foi realizado o recorte das unidades de registro, e a categorização em eixos temáticos;

3. No tratamento dos resultados, consistiu na interpretação dos dados em que foram reunidas por características comuns facilitando a apresentação dos resultados através da interpretação de interferência, cuja interpretação consistiu na apresentação dos estudos selecionados e explanação dos eixos temáticos.

\subsection{Análise e interpretação dos dados}

A análise e a interpretação dos dados foram feitas por meio da descrição dos achados. Os dados foram organizados em uma tabela Excel®, que compreendeu as seguintes colunas de sintetização: título do estudo, base de dados, periódico, ano de publicação, contexto/local de estudo, desenho metodológico, resultados e conclusões.

\subsection{Aspectos éticos}

Cabe salientar que os aspectos éticos e os direitos de autoria foram devidamente respeitados, por meio da referenciação dos autores dos trabalhos utilizados. Por se tratar de um estudo de revisão de literatura, não houve necessidade de apreciação por um Comitê de Ética em Pesquisa (CEP).

\section{Resultados e Discussão}

Foram considerados, inicialmente, 205 estudos com a temática proposta; dentre estes, foram excluídos 105 estudos, de acordo com os critérios de exclusão estabelecidos. Após a aplicação dos critérios de inclusão, restaram 18 estudos. Com os estudos incluídos foram feitas revisões críticas e corroborativas sobre cada um deles.

Sabe-se que as vacinas são uma das intervenções voltada saúde pública que apresenta melhores resultados. Pois na maior parte dos casos leva-se anos de desenvolvimento, mas a necessidade urgente de uma vacina eficaz para suprimir a transmissão da SARS-CoV-2. Em certos casos as vacinas podem expressar alguns efeitos adversos, como reações de hipersensibilidade (HSRs). Dada sua recente disponibilidade e novo mecanismo de ação, as informações sobre possíveis HSRs e sua incidência são limitadas. 
Embora pareça raro, espera-se que muitos indivíduos sejam afetados devido à implementação da vacinação em massa em todo o mundo (Carvalho et al., 2021).

No Brasil, o Ministério da Saúde (MS) apresentou como medida de combate à doença o chamado Plano Nacional de Operacionalização da Vacinação contra a COVID-19, definido como Emergência de Saúde Pública de Importância Internacional (Brasil, 2021).

Araújo et al. (2021) descreveram que as vacinas na profilaxia de doenças se apresentam uma melhor alternativa de custobenefício no âmbito da saúde pública. No Brasil, o Programa Nacional de Imunizações (PNI) vinculado ao SUS vem desenvolvendo metas ao longo dos anos, disponibilizando de forma gratuita imunização contra diversas doenças de importância epidemiológica, como sarampo, hepatite B, febre amarela e poliomielite, esta última considerada erradicada no país (Araújo et al., 2021).

Todas as vacinas necessitam de pesquisas preliminares, testes e monitorização de estudos clínicos de fase I, II e III, posteriormente a apresentação de resultados favoráveis de eficácia e segurança podem então prosseguir para a fase IV pósaprovação e pós-comercialização onde a análise se dá mediante ao uso pela população no geral (Araújo et al., 2021).

No estudo realizado por Martins et al. (2021), relataram dez motivos para a indicação da vacina na Figura 1. O estudo também descreveu a importância da manutenção das eficazes e comprovadas medidas de prevenção ao contágio pela COVID-19: higienização das mãos, uso de máscaras e distanciamento social.

Figura 1. Dez razões para vacinar o paciente contra COVID-19.

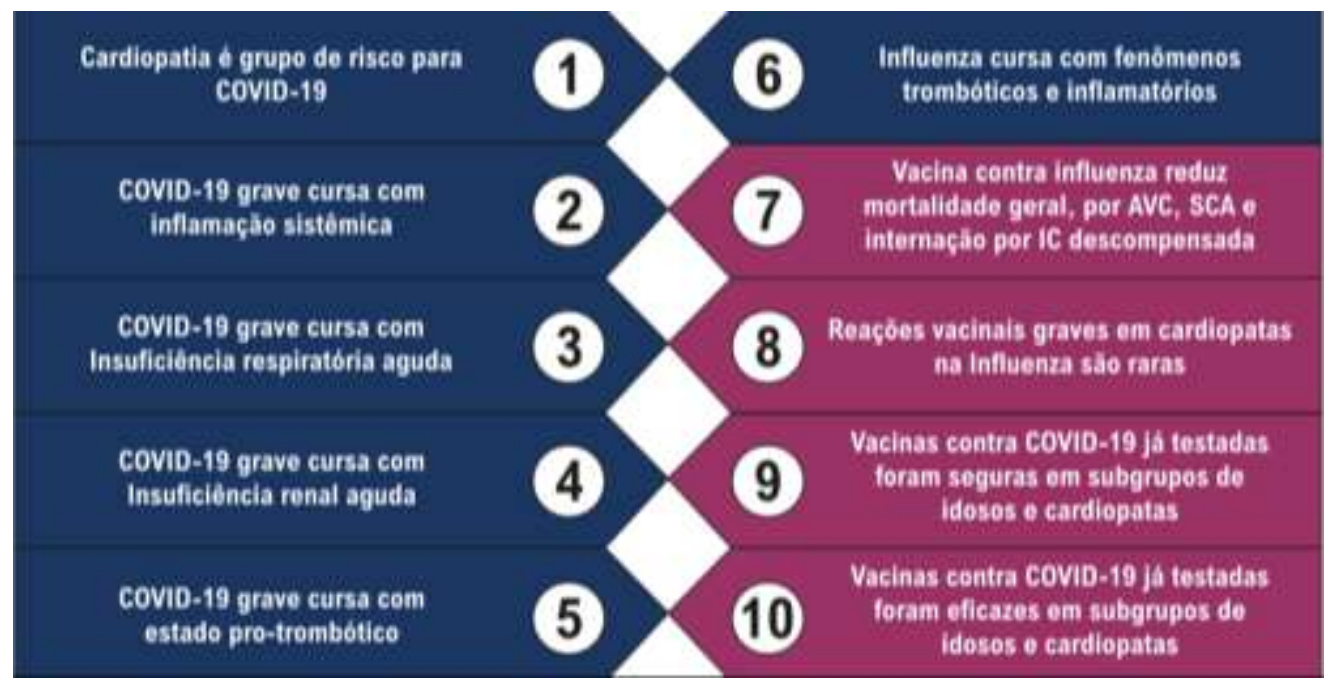

AVC: acidente vascular cerebral; SCA: síndrome coronariana aguda; IC: insuficiência cardíaca. Fonte: Martins et al. (2021).

Creech; Walker; Samuels, (2021), descrevem que diversas pesquisas de vacinas foram avaliados por diferentes grupos. As vacinas SARS-CoV-2 atualmente autorizadas para uso e outras que possuem dados clínicos de estágio avançado disponíveis estão resumidas na Figura 2. 
Figura 2. projetos de vacinas.

\begin{tabular}{|c|c|c|c|c|c|c|}
\hline VACINA & FABRICANTE & TIPO & DOSAGEM & $\begin{array}{l}\text { EFICÁCIA NOS CASOS } \\
\text { GRAVES }\end{array}$ & EFICÁCIA GLOBAL & $\begin{array}{l}\text { RESUMO } \\
\text { NL. ISBE }\end{array}$ \\
\hline mRNA-1273 & Moderna (US) & mRNA & $\begin{array}{l}2 \text { doses com } 28 \text { dias } \\
\text { de intervalo }\end{array}$ & $100 \% 14$ dias após a 2a dose & $\begin{array}{l}92 \% 14 \text { dias após a } 1 \text { a dose; } 94 \% 14 \text { dias após a } 2^{\text {a }} \\
\text { dose }\end{array}$ & 75 \\
\hline BNT162b2 & $\begin{array}{l}\text { Pfizer-BioNTech } \\
\text { (US) }\end{array}$ & mRNA & $\begin{array}{l}2 \text { doses com } 21 \text { dias } \\
\text { de intervalo }\end{array}$ & $89 \%$ depois da 1 a dose & $52 \% 14$ dias após a 1 dose; $97 \% 7$ dias após a 2 dose & $\underline{73}$ \\
\hline Ad26.Cov2.5 & $\begin{array}{l}\text { Johnson \& } \\
\text { Johnson (US) }\end{array}$ & Vector viral & 1 dose única & $\begin{array}{l}85 \% \text { após } 28 \text { dias e } 100 \% \\
\text { após } 49 \text { dias }\end{array}$ & $\begin{array}{l}72 \% \text { nos EUA, } 66 \% \text { na América Latina; } 57 \% \text { na África } \\
\text { do Sul (aos } 28 \text { dias) }\end{array}$ & \\
\hline $\begin{array}{l}\text { ChAdOx1 } \\
\text { (AZS1222) }\end{array}$ & $\begin{array}{l}\text { AstraZeneca/ } \\
\text { Oxford (UK) }\end{array}$ & Vector viral & $\begin{array}{l}2 \text { doses com } 28 \text { dias } \\
\text { de intervalo }\end{array}$ & $100 \% 21$ dias após a 1a dose & $64 \%$ após a 1 a dose; $70 \% 14$ dias após a 2a dose & $\underline{71}$ \\
\hline NVX-CoV2373 & Novavax, Inc (US) & Subunidade proteica & 2 doses & Desconhecida & $89 \%$ após as 2 doses (UK); $60 \%$ na África do Sul & \\
\hline CVnCoV & $\begin{array}{l}\text { CureVac/GSK } \\
\text { (Germany) }\end{array}$ & mRNA & $\begin{array}{l}2 \text { doses com } 28 \text { dias } \\
\text { de intervalo }\end{array}$ & Desconhecida & Ensaio fase 3 a decorrer & \\
\hline $\begin{array}{l}\text { Gam-COVID- } \\
\text { Vac } \\
\text { (Sputnik V) }\end{array}$ & $\begin{array}{l}\text { Gamaleya Nat Res } \\
\text { Ctr Epidemiol and } \\
\text { Microbiol (Russia) }\end{array}$ & Vector viral & $\begin{array}{l}2 \text { doses com } 21 \text { dias } \\
\text { de intervalo }\end{array}$ & $100 \% 21$ dias após a 1a dose & $88 \% 14$ dias após a 1 a dose; $91 \% 7$ dias após a $2^{2}$ dose & $\underline{86}$ \\
\hline CoronaVac & $\begin{array}{l}\text { Sinovac Biotech } \\
\text { (China) }\end{array}$ & Vírus inactivado & $\begin{array}{l}2 \text { doses com } 14 \text { dias } \\
\text { de intervalo }\end{array}$ & Desconhecida & Dados RCT fase 3 não disponiveis & \\
\hline BBIBP-CorV & $\begin{array}{l}\text { Sinopharm } 1 / 2 \\
\text { (China) }\end{array}$ & Virus inactivado & $\begin{array}{l}2 \text { doses com } 21 \text { dias } \\
\text { de intervalo }\end{array}$ & Desconhecida & Dados RCT fase 3 não disponiveis & \\
\hline
\end{tabular}

Fonte: Creech; Walker; Samuels (2021).

Quanto a produção de vacinas, o Informe Técnico nacional da campanha de vacinação contra a COVID-19, levou a público o panorama da OMS relatando a existência de 173 vacinas candidatas em fase pré-clínica de pesquisa e 63 vacinas candidatas em fase de pesquisa clínica, dessas 20 alcançaram a fase III de ensaios clínicos. Onde duas inicialmente foram selecionadas como capazes à introdução na rede pública de saúde do PNI, sendo estas as vacinas CoronaVac proveniente da Farmacêutica Sinovac/Butantan e a AstraZeneca produzida pela Universidade de Oxford em parceria com a Fundação Oswaldo Cruz (Fiocruz) e com o Instituto Serum da Índia, constituídas respectivamente pelo vírus inativado SARS-CoV-2 e o adenovírus recombinante (Brasil, 2021).

\section{CoronaVac}

Os vírus inativados purificados ganharam uma papel relevante na produção de vacinas e, nos dias atuais, oito vacinas candidatas COVID-19 inativadas foram avaliadas clinicamente durante a pandemia. Embora os resultados de eficácia contra COVID-19 ainda não estejam disponíveis Wu et al. (2021), descreveram que diversos estudos mostram que as vacinas inativadas podem induzir respostas de anticorpos neutralizantes e apresentam bons perfis de segurança. Entre essas vacinas temos a CoronaVac que é uma vacina SARS-CoV-2 inativada desenvolvida pela Sinovac Life Sciences (Pequim, China).

No estudo realizado por Hitchings et al. (2021), relatou que a CoronaVac apresentou resposta eficácia de $50 \%$ e $84 \%$ contra, respectivamente, COVID-19 leve e moderado em um ensaio clínico randomizado (RCT) realizado no Brasil antes do surgimento da variante P.1. No estudo foi realizado um caso-controle com teste negativo sobre a eficácia do CoronaVac em profissionais de saúde (PS) em Manaus, pois foi uma das primeiras cidades do Brasil a efetuar a vacinação em massa. Além disso a aplicação de pelo menos uma dose de CoronaVac manifestou eficácia contra a infecção sintomática por SARS-CoV-2 no cenário de transmissão da P.1.

Ranzani et al. (2021), conduziram um estudo caso-controle com teste negativo, no qual foi realizado a administração de duas doses da CoronaVac. A partir disso foi observado casos de COVID-19 confirmados por RT-PCR, bem como controles que tiveram uma doença sintomática com um teste de RT-PCR negativo de vigilância nacional. Selecionamos 7.950 pares pareados com idade média de 76 anos de 26.433 casos COVID-19 e 17.622 controles com teste negativo. A eficácia da vacina ajustada foi de 18,2\% (IC de 95\%, 0,0 a 33,2) e 41,6\% (IC de 95\%, 26,9 a 53,3) no período de 0-13 e $\geq 14$ dias, respectivamente, após a $2^{\text {a }}$ dose. 
Faria et al. (2021), buscaram relatar a ocorrência de COVID-19 sintomático em uma coorte de profissionais de saúde vacinados com CoronaVac. Desde a $1^{\mathrm{a}}$ dose, havia 380 profissionais de saúde com diagnóstico de COVID-19. A eficácia estimada 2 e 3 semanas após a $2^{\text {a }}$ dose foi de 50,7\% e 51,8\%, respectivamente, e elevou nas 2 semanas seguintes. 67/142 amostras (47\%) foram variantes preocupantes, principalmente P1.

\section{AstraZeneca/Universidade de Oxford}

A vacina ChAdOx1 nCoV-19 (AZD1222) ou AstraZeneca COVID-19 foi desenvolvida na Universidade de Oxford no caso é realizada a partir de um vetor adenoviral de chimpanzé deficiente para replicação ChAdOx1, onde contém o antígeno de glicoproteína de superfície estrutural SARS-CoV-2 (proteína spike; nCoV-19) gene. Esse vacina apresentou um perfil de segurança aceitável e foi considerado eficaz contra COVID-19. Além disso, ChAdOx1 nCoV-19 é tolerado em idosos e jovens e tem imunogenicidade semelhante em todas as idades (Addi; Benksim; Cherkaoui, 2021).

Khan Sharun; Dhama. (2021), relataram que vacina de vetor viral AstraZeneca / Oxford exibiu uma eficácia média de 70,4\%. Além disso foi avaliada em participantes com 18 anos ou mais. O ensaio clínico randomizado conduzido no Brasil, Reino Unido e África do Sul confirmou a segurança e eficácia do AZD1222 contra COVID-19 sintomático, com isso descoberto que a vacina AstraZeneca / Oxford COVID-19 possui imunogenicidade semelhante em todas as faixas etárias após a dose de reforço.

Embora a eficácia da vacina AstraZeneca, seja inferior às produzidas pela Pfizer, alguns pontos devem ser considerados, como no caso das condições de armazenamento. A Pfizer exige remetentes com temperatura controlada para o transporte de vacinas, durante o armazenamento recomenda-se utilizar de $-70{ }^{\circ} \mathrm{C} \pm 10^{\circ} \mathrm{C}$ em até 15 dias. Caso ocorra o descongelamento, a vacina só pode ser armazenada em condições de refrigeração $\left(2-8^{\circ} \mathrm{C}\right)$ por até 5 dias. No entanto, AZD1222 nCoV-19 pode ser transportado, armazenado e distribuído em condições de refrigeração $\left(2-8^{\circ} \mathrm{C}\right)$ por um mínimo de seis meses usando os ambientes de saúde existentes (Khan Sharun; Dhama, 2021).

Wise et al. (2021), descreveu um estudo envolvendo 17.177 participantes no Reino Unido, Brasil e África do Sul. Onde aquele que receberam somente uma dose padrão de vacina forneceu 76\% de proteção geral contra COVID-19 sintomático durante os primeiros 90 dias após a vacinação, observando a não diminuição da eficácia durante neste período. No entanto não está claro, quanto tempo a proteção pode durar com uma única dose, devido a pequena quantidade de casos após 90 dias. As análises apontam que é o intervalo de dosagem e não o nível de dosagem que tem o maior impacto na eficácia da vacina. Isso está de acordo com pesquisas anteriores que apoiam uma maior eficácia com intervalos mais longos com outras vacinas, como influenza e Ebola. O estudo concluiu que a eficácia da vacina atingiu 82,4\% após uma segunda dose naqueles com um intervalo de dosagem de 12 semanas ou mais. Se as duas doses foram administradas com menos de seis semanas de intervalo, a eficácia cai para $54,9 \%$.

Com a produção da vacina de Oxford/AstraZeneca-Fiocruz em território nacional, e a entrega de lotes ao Ministério da Saúde, esta etapa começa a dar os primeiros resultados à sociedade brasileira. Ainda em 2021, o Brasil terá uma vacina produzida totalmente no Brasil e iniciará a fabricação dos primeiros lotes do insumo farmacêutico ativo (IFA), que deverá estar acessível para a população no segundo semestre. Porém a Fiocruz continua, atuando no desenvolvimento de outros projetos que levem a novos imunizantes contra a COVID-19. No momento, a Fiocruz desenvolve sete outras vacinas, com parceiros diversos, nacionais e estrangeiros (Informe, 2021).

\section{Pfizer/BioNTech}

A vacina da Pfizer dá-se a partir do mRNA, onde é utilizado o RNA mensageiro sintético, que atua no organismo do indivíduo a gerar anticorpos contra o vírus. Pode ser desenvolvida e fabricada de maneira mais rápida e efetiva quando comparada 
com as vacinas tradicionais. A Pfizer selecionou essa tecnologia de vacina baseada em mRNA devido ao seu potencial de alta resposta, segurança e capacidade de rápida produção. A tecnologia de mRNA pode ainda ser estratégica para cenários de pandemias e epidemias devido à agilidade em modificação do antígeno codificado caso necessário, bem como a potencialidade de realização de doses de reforço. A técnica, na qual apenas um pedaço de material genético é usado em vez de todo o vírus, nunca havia sido feita antes (Pfizer, 2021).

O Ministério da Saúde (MS), incluiu a vacina Pfizer na Campanha Nacional de Vacinação contra a COVID-19. Ressaltase que, assim como as outras vacinas disponíveis, a vacina COVID-19 Pfizer compõe o Plano Nacional de Operacionalização (PNO) e, portanto, sua indicação seguirá os critérios e ordenamento das prioridades. Sendo que o esquema corresponde a 02 (duas) doses (0,3 ml cada) com um intervalo de 21 dias entre as doses (preferencialmente 03 semanas) (Brasil, 2021).

Foram avaliadas reações adversas mais frequentes em participantes com idade igual ou superior a 16 anos, em ordem das frequências das mais altas para as mais baixas (Figura 3).

Figura 3: Eventos Adversos Pós Vacinação da vacina Pfizer.
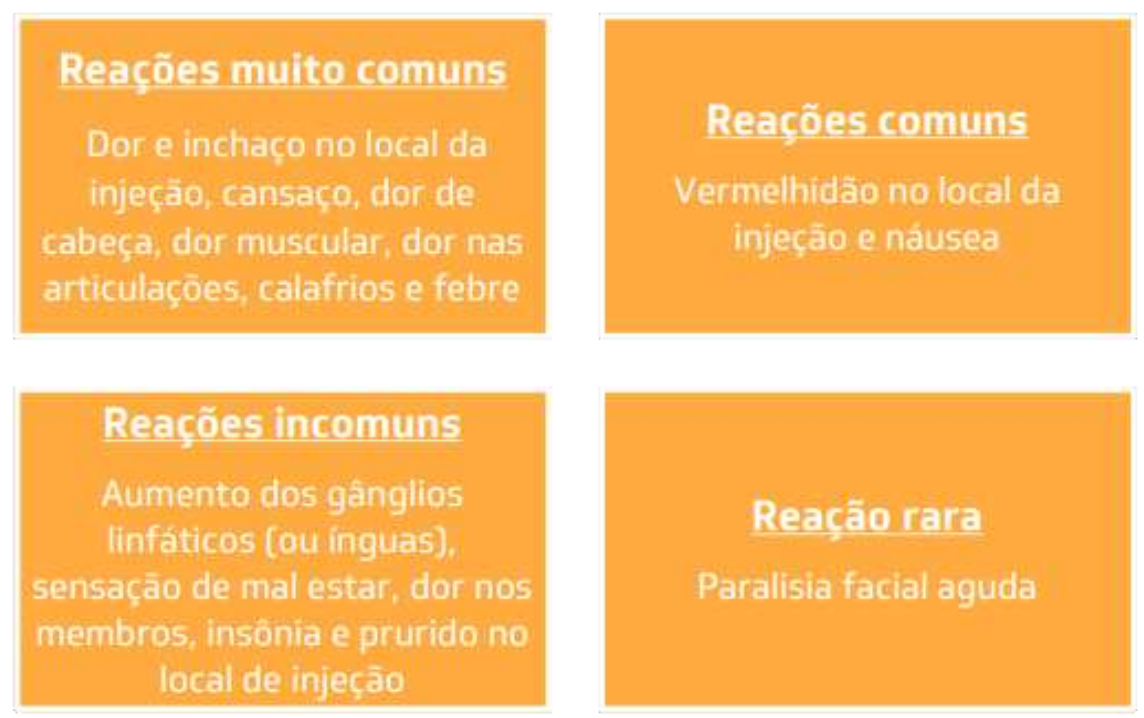

Fonte: Brasil (2021).

\section{Conscientização da imunização}

Observa-se que entre os pontos a serem discutidos estão os desafios para a estruturação de campanhas de saúde efetivas, a definição e localização da população-alvo. Pois somente a partir da correta identificação do público-alvo torna-se possível compreender os recursos fundamentais e os custos relacionados a campanhas em saúde. Estimar a população-alvo de uma campanha é uma tarefa desafiadora, uma vez que a principal fonte de dados para tal ação são os censos populacionais. Para muitos países, não há informações atualizadas originárias de censos para os últimos 15 anos (Rocha et al., 2021).

A tomada de decisão a respeito da vacinação é um fenômeno comportamental complexo em relação aos seus determinantes. Pois observa-se que está associado a aspectos culturais, geográficos, psicossociais, econômicos, religiosos, políticos, fatores cognitivos e de gênero. As razões para a hesitação vacinal se encaixam em três categorias inter-relacionadas: a primeira é a falta de confiança na eficácia, na segurança, no sistema de saúde que disponibiliza as vacinas ou nas motivações dos gestores e formuladores de políticas para recomendá-las, por segundo a complacência, onde observa-se uma pequena percepção do risco de adquirir doenças imunopreveníveis, a partir disso pressupõem que a vacinação não seria necessária e por terceiro a falta de conveniência, visando assim, a disponibilidade, acessibilidade e o apelo dos serviços de imunização, incluindo tempo, 
lugar, idioma e contextos culturais (Oliveira et al., 2021).

Couto; Barbieri; Mato (2021), relataram que os planos de prevenção buscam em si o conflito entre o individual e o coletivo. Já as normatizações, regulamentações e recomendações são provenientes de órgãos ou instituições de saúde que estão relacionadas às coletividades, as tomadas de decisão para implementá-las são indivíduo-centradas e ocorrem predominantemente a partir de referências próprias ao sujeito, conformadas e compartilhadas em seu entorno. Tanto a vacinação quanto a pandemia de COVID-19 trazem à tona o conflito individual $\times$ coletivo.

O mesmo estudo expões que a "imunidade coletiva" ou "de rebanho" é obtida a partir da vacinação realizada em massa e atinge elevada cobertura. Essa imunidade possibilita, além da proteção individual da pessoa vacinada, a eliminação da circulação do agente infeccioso no meio e a proteção indireta das pessoas suscetíveis, como no caso daquele que apresentam alguma contraindicações à vacina como prematuros, gestantes ou pessoas com imunidade comprometida, além daquelas não vacinadas (Couto; Barbieri; Mato, 2021).

A Anvisa publicou o Protocolo de Vigilância Epidemiológica e Sanitária de Eventos Adversos Pós-Vacinação com o objetivo de determinar medidas e diretrizes para a atuação dos agentes da vigilância sanitária e epidemiológica das vacinas contra o vírus SARS-CoV-2, de forma a avaliar a segurança do produto a partir da análise de eventos adversos pós-vacinação (EAPV). A partir disso, a Anvisa pretende controlar e detectar casos suspeitos de EAPV, atuando na busca e a avaliação de causalidade de cada um deles (Silva et al., 2021).

\section{Considerações Finais}

No início de 2021, com o desenvolvimento de múltiplas vacinas com eficácia e segurança comprovadas, o principal desafio relacionado à resposta COVID-19 é garantir a imunização em massa oportuna. Uma das maiores conquistas da saúde coletiva é a vacinação por seus benefícios imensuráveis, reduzindo de forma significativa, controlando e erradicando agravos. Ao longo da história observa-se que as práticas de vacinação programadas e organizadas evitam milhões de óbitos e controla a evolução de várias doenças.

No Brasil, a cobertura vacinal se iniciou por dois grupos prioritários: profissionais da saúde por estarem na linha de frente e população idosa, pelo maior risco de morte por COVID-19 que aumenta com a idade, especialmente entre os portadores de doenças crônicas. Acompanhada de perto pela sociedade e frequentemente exposta em mídias sociais, a sequência da cobertura vacinal de acordo com os grupos prioritários, deve ser gerenciada e rigorosamente monitorada por profissionais da saúde.

Os laboratórios responsáveis pela produção da CoronaVac, Oxford/AstraZeneca e Pfizer/BioNTech recomendam a aplicação de duas doses de imunizante para um combate mais eficiente à doença.

\section{Referências}

Addi, R. A., Benksim, A., \& Cherkaoui, M. (2021). A vacinação contra COVID-19 no Marrocos: uma história de sucesso em andamento. Signa Vitae , 17 (3), $250-255$.

Araújo, I. G., de Souza Oliveira, E., Pires, V. R., \& de Morais, A. C. L. N. (2021). Imunopatologia do SARS-CoV-2 e análise dos imunizantes no território brasileiro. Revista de Casos e Consultoria, 12(1), e23990-e23990.

Bardin, L. (2011). Analise de Conteúdo. Ed. Revista Ampliada.

Brasil. Ministério da saúde. CORONAVÍRUS/BRASIL. Secretarias Estaduais de Saúde. https://covid.saude.gov.br/

Brasil. Secretaria de Estado da Saúde. Nota Técnica: Vacina Covid-19 Pfizer - BioNtech. Ceará. https://www.saude.ce.gov.br/wp-content/uploads/sites/9/2020/02 130_04_2021-Nota-Te\%CC\%81cnica-_-Pfizer.pdf

Carvalho, J. C., Cunha, F., Coutinho, I. A., Loureiro, C., Faria, E., \& Bom, A. T. (2021). Hypersensitivity Reactions to Vaccines: Current Evidence and Standards for SARS-CoV-2 Vaccines. Acta Médica Portuguesa, 34(13). 
Corrêa Filho, H. R., \& Ribeiro, A. A. (2021). Vacinas contra a Covid-19: a doença e as vacinas como armas na opressão colonial.

Couto, M. T., Barbieri, C. L. A., \& Matos, C. C. D. S. A. (2021). Considerações sobre o impacto da covid-19 na relação indivíduo-sociedade: da hesitação vacinal ao clamor por uma vacina. Saúde e Sociedade, 30, e200450.

Creech, C. B., Walker, S. C., \& Samuels, R. J. (2021). SARS-CoV-2 vaccines. Jama, 325(13), 1318-1320.

Domingues C. M. A. S. Desafios para a realização da campanha de vacinação contra a COVID-19 no Brasil. Cadernos de Saúde Pública, 2021; $37(1)$ : 1-5.

Faria, E., Guedes, A. R., Oliveira, M. S., Moreira, M. V. G., Maia, F. L., Barboza, A. S., \& Levin, A. S (2021). Desempenho da vacinação com CoronaVac em uma coorte de profissionais de saúde (HCW) - relatório preliminar. medRxiv .

Hitchings, M. D., Ranzani, O. T., Torres, M. S. S., de Oliveira, S. B., Almiron, M., Said, R., \& Croda, J. (2021). Eficácia do CoronaVac no contexto de transmissão da variante SARS-CoV-2 P. 1 alta no Brasil: Um estudo caso-controle com teste negativo. medRxiv

Informe, E. N. S. P. (2021). Fiocruz desenvolve novas vacinas para enfrentar Covid-19.

Khan Sharun, R. S., \& Dhama, K. (2021). A vacina Oxford-AstraZeneca COVID-19 (AZD1222) é ideal para países de baixa e média renda com recursos limitados. Annals of Medicine and Surgery.

Lima, E. J. D. F., Almeida, A. M., \& Kfouri, R. D. Á. (2021). Vacinas para COVID-19-o estado da arte. Revista Brasileira de Saúde Materno Infantil, 21, 13-19.

Martins, W. D. A., Oliveira, G. M. M. D., Brandão, A. A., Mourilhe-Rocha, R., Mesquita, E. T., Saraiva, J. F. K., \& Lopes, M. A. C. Q. (2021). Vacinação do Cardiopata contra COVID-19: As Razões da Prioridade. Arquivos Brasileiros de Cardiologia, 116(2), 213-218.

Mendes, K. D. S., Silveira, R. C. D. C. P., \& Galvão, C. M. (2008). Revisão integrativa: método de pesquisa para a incorporação de evidências na saúde e na enfermagem. Texto \& contexto-enfermagem, 17(4), 758-764.

Nalbandian, A., Sehgal, K., Gupta, A., Madhavan, M V., McGroder, C., Stevens, \& Wan, E. Y (2021). Síndrome pós-aguda de COVID-19. Nature medicine , 115 .

Oliveira, B. L. C. A. D., Campos, M. A. G., Queiroz, R. C. D. S., Alves, M. T. S. S. D. B., Souza, B. F. D., Santos, A. M. D., \& Silva, A. A. M. D. (2021). Prevalência e fatores associados à hesitação vacinal contra a covid-19 no Maranhão, Brasil. Revista de Saúde Pública, 55, 12.

PANG, Junxiong et al. Potential rapid diagnostics, vaccine and therapeutics for 2019 novel coronavirus (2019-nCoV): a systematic review. Journal of clinical medicine, 9, 623.

Pfizer Press Release. COVID-19 - Principais Perguntas \& Respostas Sobre Vacina PFIZER e BIONTECH. Pfizer. https://www.pfizer.com.br/sua-saude/covid-19coronavirus/covid-19-principais-perguntas-respostas-sobre-vacina-pfizer-e-biontech

Ranzani, O. T., Hitchings, M., Dorion, M., D'Agostini, T. L., de Paula, R. C., de Paula, O. F. P., \& Croda, J. (2021). Eficácia da vacina CoronaVac na população idosa durante uma epidemia associada à variante P. 1 de COVID-19 no Brasil: Um estudo caso-controle com teste negativo. medRxiv .

Rocha, T. A. H., Boitrago, G. M., Mônica, R. B., Almeida, D. G. D., Silva, N. C. D., Silva, D. M., \& Vissoci, J. R. N. (2021). Plano nacional de vacinação contra a COVID-19: uso de inteligência artificial espacial para superação de desafios. Ciência \& Saúde Coletiva, 26, 1885-1898.

Silva, V. E. (2021). A Responsabilidade Civil do Estado e dos fornecedores pelos riscos da aplicação da vacina contra a Covid-19.

Ventura, D. D. F. L., Aith, F. M. A., \& Rached, D. H. (2021). A emergência do novo coronavírus e a "lei de quarentena" no Brasil. Revista Direito e Práxis, 12 (1), 102-138.

V'kovski, P., Kratzel, A., Steiner, S., Stalder, H., \& Thiel, V. (2021). Biologia e replicação do coronavírus: implicações para o SARS-CoV-2. Nature Reviews Microbiology, 19 (3), 155-170.

Tesini, B. L. (2020). Coronavírus e Síndromes respiratórias agudas (COVID-19, MERS e SARS). Manual MSD para profissionais da saúde.

Wise, J. (2021). Covid-19: Novos dados sobre a vacina Oxford AstraZeneca atrasam o intervalo de dosagem de 12 semanas.

Wu, Z., Hu, Y., Xu, M., Chen, Z., Yang, W., Jiang, Z., \& Yin, W. (2021). Segurança, tolerabilidade e imunogenicidade de uma vacina inativada contra SARSCoV-2 (CoronaVac) em adultos saudáveis com 60 anos ou mais: um ensaio clínico de fase $1 / 2$ randomizado, duplo-cego, controlado por placebo. The Lancet Infectious Diseases. 